\title{
O GUME DA IRONIA EM MACHADO DE ASSIS E JANE AUSTEN
}

\author{
SANDRA GUARDINI TEIXEIRA VASCONCELOS \\ Universidade de São Paulo \\ São Paulo, São Paulo, Brasil
}

Resumo: A partir de uma observação de John Gledson, que sugere "uma profunda afinidade entre Machado de Assis e Austen, sobretudo em sua ironia onipresente, meticulosa e implicitamente agressiva" (cf. "A parasita azul"), tenciono investigar o potencial dessa afinidade, interrogando os usos que ambos fizeram da ironia como arma de crítica social e as possíveis diferenças que se podem estabelecer entre o modo como cada escritor a mobiliza para dar conta de representar o mundo que era o seu.

Palavras-chave: ironia, romance; Machado de Assis; Jane Austen; crítica social.

\section{BITING IRONY IN MACHADO DE ASSIS AND JANE AUSTEN}

Abstract: Using John Gledson's suggestion that there is "a profound affinity between Machado de Assis and Austen, particularly in their omnipresent, meticulous and implicitly aggressive irony" (cf. "A Parasita azul"), as a starting point, this article intends to investigate the potential of said affinity by interrogating the uses which both authors made of irony as an instrument of social criticism and the possible differences which can be established between the way each writer mobilizes it in order to represent their world.

Keywords: irony; novel; Machado de Assis; Jane Austen; social criticism.

\section{Aproximações}

primeira vista, parece bastante arriscado tentar uma aproximação
entre Machado de Assis e Jane Austen. Afinal de contas, não existem
evidências de que o escritor brasileiro tenha tido qualquer contato com
a obra da romancista inglesa, ainda que todos os seus romances estivessem
disponíveis no acervo da Rio de Janeiro British Subscription Library e que $A$
Família Elliot, ou a inclinação antiga, tradução portuguesa de Persuasion
publicada em Lisboa em 1847 tivesse circulado na Corte e pudesse ser 
encontrada em alguns dos gabinetes de leitura da cidade. ${ }^{1}$ Diante da falta de indícios concretos, portanto, o que justificaria estabelecer esse colóquio altamente implausível entre dois autores em tudo e por tudo tão diversos?

A intimidade de Machado com a literatura inglesa tem uma longa história, que data pelo menos desde a resenha publicada por Artur Barreiros em Pena $\mathcal{G}$ Lápis em junho de 1880, ${ }^{2}$ quando Memórias póstumas de Brás Cubas ainda estava saindo em fascículos na Revista Brasileira, na qual o resenhista procura explicar a singularidade deste "romance extraordinário" pelo seu parentesco com a linhagem dos humoristas ingleses. Sabemos o quanto rendeu essa associação entre Machado, o humour e os ingleses na fortuna crítica do escritor. Salvo engano, foi John Gledson, porém, quem traçou pela primeira vez, em ensaio sobre "A Parasita Azul", ${ }^{3}$ o surpreendente paralelo entre Machado e Austen. Improvável, pelas incontornáveis diferenças entre eles, a afinidade é ali sugerida graças ao recurso, por parte de ambos, à ironia como instrumento poderoso que os narradores mobilizam para produzir uma crítica mordaz e expor as falhas que observam na ordem social, revelando assim o funcionamento das engrenagens que regulam a vida em sociedade. Tenciono explorar essa afinidade, discutindo a filiação de ambos os romancistas à tradição da "agressão cômica" e as consequências dessa filiação para o modo como cada um representa as relações sociais de seu tempo. Ainda que indiretas, as conexões poderiam ser rastreadas à adoção de uma mesma atitude no tratamento de seu material, a qual se entronca num ramo comum e numa certa conformidade de pontos de vista em relação ao mundo e aos homens. Por esse viés, não apenas uma grande carga de ironia é imputada à figura do narrador, como também personagens, muitas delas bastante centrais, podem assumir o papel de "agressores". No caso de Austen, a "agressão cômica" pode ser de três tipos: social, que envolve os diferentes modos de revidar os limites

\footnotetext{
${ }^{1}$ Publicado postumamente com Northanger Abbey, foi traduzido para o francês como La Famille Elliot, ou l'ancienne inclination (traduit de l'anglais de miss Jane Austen par Mme. de Montolieu) e daí para o português como A Família Elliot, ou a inclinação antiga (trad. do francês por Manuel Pinto Coelho Cota de Araújo. Lisboa: Rollandiana, 1847, 2 vol. in-8). No século XIX, essa edição foi anunciada no Diário do Rio de Janeiro por B. L. Garnier em 29 de novembro e 19 de dezembro de 1854 e podia ser encontrada no Real Gabinete Português de Leitura do Rio de Janeiro [ver $3^{\circ}$. Suplemento ao catálogo de 1844; catálogo de 1858], na Biblioteca Fluminense [catálogos de 1852 e 1866], na Laemmert [catálogo de 1868]. AUSTEN, Persuasion.

${ }^{2}$ Citado por Hélio de Seixas Guimarães. GUIMARÃES, Machado de Assis e o paradigma inglês, p. 39.

${ }^{3}$ GLEDSON, 1872: "A parasita azul". Ficção, nacionalismo e paródia, p. 163-218.
} 
impostos pela vida em sociedade; interpessoal, que apreendemos nas situações de conflito entre duas personagens; e interno, quando o conflito é internalizado por uma personagem e sua invectiva se dirige a si própria. ${ }^{4} \mathrm{Os}$ romances de Jane Austen estão coalhados de exemplos desses três tipos de "agressão cômica", que funciona como um gume crítico para expor os defeitos, as deficiências e a hipocrisia que o narrador observa nos comportamentos e caráter de suas criaturas, mas também, em algumas circunstâncias, para dramatizar momentos de reflexão, autoexame e descoberta por parte de alguma personagem.

O que essa perspectiva oferece, e é isso que importa sublinhar, é um ponto de vista profundamente crítico à sociedade da época que desmonta a imagem da "sweet aunt $\mathrm{Jane}{ }^{5}$ que a família da escritora quis promover e legar à posteridade. Ao contrário, a leitura cerrada dos romances, das situações, do modo de construção das personagens e a atenção à postura e à linguagem do narrador demonstram que, apesar de integrante daquela fração de classe da qual trata nas suas narrativas, esse é um narrador que não hesita em destilar sua ironia para dar a ver o que se esconde por trás da civilidade, dos códigos de conduta e convenções de sociabilidade que caracterizam as relações sociais de seu tempo. Desse modo, suas bem-comportadas personagens, impecáveis em seus trajes no estilo Regência, tão ciosas do decoro e das normas de convívio social, soam notas de hostilidade e encenam pequenos atos de crueldade, consciente ou não, enquanto conversam e dançam nos salões da pequena nobreza do interior da Inglaterra.

Interessa, assim, explorar as implicações sociais do uso da ironia, como a arma que a condição de dependência de Jane Austen lhe facultava para observar e comentar os costumes de seu tempo. No seu universo ficcional, mesmo que mínimo e delimitado geográfica e socialmente, cabe o mundo, ou melhor, cabe toda uma experiência histórica "no pedacinho de marfim (de duas polegadas de largura) no qual trabalho com um pincel tão fino e que produz pouco efeito depois de tanto esforço", como revela Austen em carta

\footnotetext{
${ }^{4}$ WATT, Jane Austen and The Traditions of Comic Aggression, p. 159-170. Um exemplo desse último tipo de agressão cômica pode ser encontrado no solilóquio de Elizabeth Bennet, em Pride and Prejudice, quando ela descobre seu erro de julgamento em relação a Darcy: "How despicably have I acted!" she cried. -- "I who have prided myself on my discernment! - I, who have valued myself on my abilities! who have often disdained the generous candour of my sister, and gratified my vanity, in useless or blameable distrust - How humiliating is this discovery! - Yet, how just a humiliation!". AUSTEN, Pride and Prejudice, p. 236.
}

${ }^{5}$ AUSTEN-LEIGH, A Memoir of Jane Austen, p. 1. 
ao sobrinho datada de $1816 .{ }^{6}$ Suas pequenas esculturas nos facultam uma visada da condição feminina naquele momento histórico, figurada numa forma na qual sobressaem o controle absoluto da estrutura narrativa, a construção de personagens e a articulação de um ponto de vista. A ironia é o instrumento potente que o narrador austeniano mobiliza para produzir uma crítica social mordaz, que não poupa nem ao menos as heroínas ao tornar visíveis suas faltas e limitações. Para além da caricatura e da sátira, de que não raro lança mão, esse narrador adota um olhar distanciado e ferinamente crítico para expor as falhas que observa na civilizada ordem social, apreendidas por detrás da urbanidade e das boas maneiras que caracterizam os comportamentos em sociedade. D.W. Harding nomeou essa atitude de "ódio controlado", a qual não se furta a jogar luz sobre os traços mais objetáveis de suas criaturas e, ao fazê-lo, mira e mina exatamente aquele leitor que, amando seus livros, era o tipo de gente que ela detestava. ${ }^{7}$ Esse universo racional, gentil e polido, onde predominam o recato, a moderação e a cortesia, deixa entrever pelas frestas o funcionamento das engrenagens sociais e deixa a descoberto o servilismo, a arrogância, os interesses e privilégios de classe, e os preconceitos que pautam o cotidiano da vida social. Por isso, é inconcebível ler os romances de Austen em chave escapista ou romântica, só porque tratam de histórias de amor e casamento.

Debruçando-se sobre um microcosmo composto de apenas "três ou quatro famílias em um vilarejo" (carta à sobrinha, 1814), ${ }^{8}$ Austen reconstrói todo um mundo, no qual as visitas, os bailes e os passeios são os espaços privilegiados onde se tecem as relações sociais, e através do qual podemos vislumbrar problemas mais fundos que dizem respeito à condição feminina, ao dinheiro, à posição social, numa sociedade muito estratificada e presa das convenções. Descritos, embora, muitas vezes como comédias de costumes, seus romances superam essa simples definição graças ao olhar crítico, por vezes sarcástico, com que Austen lida com as questões de conduta pessoal em um mundo no qual a mobilidade social e as mudanças de fortuna passaram a afetar de modo decisivo indivíduos e famílias. Sua obra é, na verdade, a resposta de uma mulher dependente à opressão econômica e ao patriarcado. Do seu posto de observação periférico - determinado pela sua posição tanto espacial quanto social -, Austen ilumina a estrutura de

\footnotetext{
${ }^{6}$ LE FAYE, Jane Austen's Letters, p. 323.

${ }^{7}$ HARDING, Regulated Hatred: an aspect of the work of Jane Austen, p. 166-179.

${ }^{8}$ LE FAYE, cit., p. 275.
} 
funcionamento não só da "comunidade cognoscível" que era a sua, ${ }^{9}$ mas também da sociedade inglesa como um todo.

Uma das mais célebres da literatura inglesa, a abertura de Pride and Prejudice (1813) - "It is a truth universally acknowledged, that a single man in possession of a good fortune, must be in want of a wife" - 10 é esculpida com o cinzel da ironia verbal. Além do jogo de duplo sentido que se encerra em "want", que significa tanto desejo quanto necessidade, a leitura do romance logo irá revelar não só que a tal verdade universal é, de fato, a visão de uma diminuta parcela daquele meio social, aquela constituída pelas mães das moças solteiras, como também que a asserção, no fundo, não é o que parece, pois diz muito mais respeito às fantasias e expectativas das jovens dependentes do que dos rapazes disponíveis e de boa fortuna que refere. Em outros romances, Austen faz verter pela boca de Lucy Steele (Sense and Sensibility) ou Mrs. Elton (Emma) o fel que se mascara de amabilidade e polidez, seja porque movido pela ambição e espírito de competição social, no primeiro caso, ou presunção, no segundo. Outros exemplos, também de ironia situacional e dramática, são frequentes e numerosos nas diferentes narrativas, como, por exemplo, nos diálogos repletos de réplicas sagazes entre Elizabeth Bennet e Darcy, nos comentários zombeteiros e mordazes, ou nas cenas em que ao leitor é dado saber mais do que as personagens, como na visita de Elizabeth a Pemberley, ou nos encontros e conversas entre Emma e $M r$. Knightley. No trecho abaixo, não apenas surpreendemos um daqueles momentos de intrusão do narrador, com os quais ele procura guiar o ponto de vista do leitor, como ouvimos claramente sua voz irônica enquanto registra a natureza dos sentimentos de Elizabeth em relação a Darcy, ao fazer troça das paixões à primeira vista e ironizar a atração inicial de sua protagonista por Wickham:

\footnotetext{
9 Expressão cunhada por Raymond Williams para sugerir o modo particular por meio do qual o romance, enquanto forma cultural, se empenha com vigor na revelação do caráter e da qualidade das pessoas e de suas relações. Ao mesmo tempo em que diz respeito aos vínculos entre indivíduos e sociedade, o conceito também levanta questões imediatas e evidentes sobre a relação entre o escritor e seus materiais, entre sujeito e objeto, portanto, uma vez que a preocupação de Williams é compreender como a consciência do autor escolhe o que representar em um texto. O que é cognoscivel, assim, não se refere apenas ao "que há para ser conhecido", mas depende, em última instância, da "posição do observador" na comunidade e em relação a ela; ou, em outras palavras, o que há para ser conhecido depende da seleção social e do ponto de vista. WILLIAMS, O campo e a cidade: na história e na literatura, p. 228-229.
}

${ }^{10}$ AUSTEN, Pride and Prejudice, p. 51. 
If gratitude and esteem are good foundations of affection, Elizabeth's change of sentiment will be neither improbable nor faulty. But if otherwise, if the regard springing from such sources is unreasonable or unnatural, in comparison of what is so often described as arising on a first interview with its object, and even before two words have been exchanged, nothing can be said in her defence, except that she had given somewhat of a trial to the latter method, in her partiality for Wickham and that its illsuccess might perhaps authorise her to seek the other less interesting mode of attachment. ${ }^{11}$

Consideravelmente menos "luminoso, vivaz e efervescente" ("light, bright and sparkling" $)^{12}$ do que os romances anteriores, nem mesmo Persuasion abandona de todo a tradição da agressão cômica e a ironia, apesar do tom mais sombrio e melancólico. Se já não há um senso coesivo de comunidade, e a sociedade se apresenta como uma junção de partes díspares, ainda assim a unidade de enunciação assegurada pela presença forte do narrador e pelo uso magistral do discurso indireto livre (que unifica a voz narrativa e a da protagonista) ${ }^{13}$ estabelece um ponto de vista que deixa claro um código de valores, partilhado por alguns, menosprezado por outros. Para que não pairem dúvidas sobre que valores são esses, o narrador não hesita em lançar mão do humor sarcástico, da agudeza e da sátira no seu tratamento de personagens e situações. Já no primeiro capítulo, Sir Walter Elliot, um dos seus objetos de motejo, é exposto em todo o seu esnobismo, vaidade e presunção. ${ }^{14}$ Os atos de narcisismo e as preocupações mundanas, que são sua essência, desmentem e põem em chave irônica a imagem de "bom pai". O contraste entre a sutileza de penetração no plano da experiência subjetiva de Anne Elliot e a exposição da superficialidade e vacuidade de Sir Walter,

11 AUSTEN, Pride and Prejudice, p. 296. Edição brasileira: "Se a gratidão e a estima são bons fundamentos para o afeto, a mudança dos sentimentos de Elizabeth não poderia ser considerada improvável ou falha. Mas, se fosse de outro modo, se ao afeto que brotava dessas fontes faltasse razão ou naturalidade, em comparação com o que muitas vezes é descrito como o que surge no primeiro encontro, e antes mesmo de trocar duas palavras, nada pode ser dito em sua defesa senão que ela de algum modo se submetera ao último método em sua preferência por Wickham, e que o insucesso talvez a autorizasse a buscar agora o outro modo, menos interessante de se afeiçoar". AUSTEN, Orgulho e preconceito, p. 409.

12 LE FAYE, cit., p. 203.

13 Para Dorrit Cohn, Austen foi "the first extensive English practitioner" dessa técnica. COHN, Transparent Minds: Narrative Modes for Presenting Consciousness in Fiction, p. 108.

${ }^{14} \mathrm{Few}$ women could think more of their appearance than he did; nor could the valet of any new made lord be more delighted with the place he held in society. He considered the blessings of beauty as inferior only to the blessings of baronetcy: and the Sir Walter Elliot, who united these gifts, was the constant object of his warmest respect and devotion. AUSTEN, Persuasion [1985], p.36. 
Elizabeth e $M r$. William Elliot, mais própria da comédia social, só acentua o viés satírico de um dos subenredos do romance. Mesmo em uma narrativa tão marcada pela dissimulação ${ }^{15}$ e pelos movimentos da interioridade, também Anne acaba enredada em alguma ironia verbal, quando, em diferentes situações, suas palavras não podem corresponder a suas emoções. Isso ocorre, por exemplo, quando é obrigada pelos códigos de civilidade vigentes em seu meio social a pedir desculpas por ter perdido a oportunidade de se encontrar com o almirante Croft e esposa, enquanto sabemos que, na verdade, ela os evitara exatamente por causa do parentesco deles com o capitão Wentworth. Nessas ocasiões, a discrepância entre ato, expressão e sentimento, ainda que perfeitamente compreensível na economia do enredo, não passa incólume pela visão irônica que perpassa todo o texto. A adoção da perspectiva de suas protagonistas e personagens centrais não significa, assim, o abandono da prerrogativa do distanciamento crítico ou da multiplicidade enunciativa, ainda que no interior de um mesmo socioleto. A coerência entre linguagem, enredo e personagem se produz sem pôr em risco a combinação dos pontos de vista objetivo e subjetivo, nem impor uma autoridade narrativa única que chegue a obliterar as várias perspectivas em jogo.

A complexidade do ponto de vista em Austen decorre do recurso a técnicas narrativas que compreendem diferentes estratégias pelas quais essa autoridade é contida ou posta em xeque. Muitas vezes a voz do narrador desaparece por longos períodos, ou ela é reticente na avaliação de acontecimentos ou personagens, outras vezes se materializa e se faz ouvir como uma personagem, ou ainda se oculta por trás de uma personagemrefletora (como é o caso de Elizabeth, Emma e Anne), misturando sua voz à dela e mimetizando sua fala, pensamento e opinião, ou, finalmente, fala como um ventríloquo, nas palavras de Massimiliano Morini, assumindo a voz ou a opinião de todo tipo de personagem. ${ }^{16}$ Pela sua natureza camaleônica, Morini sugere caracterizar a linguagem narrativa e a ironia de Austen por meio do conceito de "perspectival disengagement"17 que, segundo ele, apreenderia de modo mais neutro e geral a "competência do narrador de subsumir as vozes das outras personagens ao mesmo tempo em que indica sutilmente que os

\footnotetext{
${ }^{15}$ Uso o termo aqui sem nenhum sentido negativo, apenas para indicar que o enredo exige que Anne oculte seus pensamentos e sentimentos, externando-os com notável parcimônia.

${ }^{16}$ MORINI, Jane Austen's Narrative Techniques: A Stylistic and Pragmatic Analysis, p. 27-53.

${ }^{17}$ Algo como "desprendimento perspectívico" ou "falta de compromisso perspectívico". MORINI, The poetics of disengagement: Jane Austen and echoic irony, p. 339-356.
} 
pontos de vista delas não são exatamente os seus". ${ }^{18} \mathrm{O}$ parágrafo de abertura de Mansfield Park é um exemplo revelador desse procedimento:

About thirty years ago, Miss Maria Ward of Huntingdon, with only seven thousand pounds, had the good luck to captivate Sir Thomas Bertram, of Mansfield Park, in the country of Northampton, and to be thereby raised to the rank of a baronet's lady, with all the comforts and consequences of an handsome house and large income. All Huntingdon exclaimed on the greatness of the match, and her uncle, the lawyer, himself, allowed her to be at least three thousand pounds short of any equitable claim to it. She had two sisters to be benefited by her elevation; and such of their acquaintance as thought Miss Ward and Miss Frances quite as handsome as Miss Maria, did not scruple to predict their marrying with almost equal advantage. But there certainly are not so many men of large fortune in the world, as there are pretty women to deserve them. Miss Ward, at the end of half a dozen years, found herself obliged to be attached to the Rev. Mr. Norris, a friend of her brother-in-law, with scarcely any private fortune, and Miss Frances fared yet worse. Miss Ward's match, indeed, when it came to the point, was not contemptible, Sir Thomas being happily able to give his friend an income in the living of Mansfield, and Mr. and Mrs. Norris began their career of conjugal felicity with very little less than a thousand a year. But Miss Frances married, in the common phrase, to disoblige her family, and by fixing on a Lieutenant of Marines, without education, fortune, or connections, did it very thoroughly. She could hardly have made a more untowardly choice. [...] Lady Bertram, who was a woman of very tranquil feelings, and a temper remarkably easy and indolent, would have contented herself with merely giving up her sister, and thinking no more of the matter; but Mrs. Norris had a spirit of activity, which could not be satisfied till she had written a long and angry letter to Fanny, to point out the folly of her conduct, and threaten her with all its possible ill consequences. ${ }^{19}$

É notável o que essa pequena crônica familiar contém em termos da habilidade desse narrador onisciente de dar voz à visão de personagens específicas (como a do tio advogado), de mimetizar a opinião pública, ou de inserir pequenos comentários ou descrições que se revelarão profundamente irônicos à medida que a ação se desenrola - como caracterizar o torpor de Lady Bertram como "temperamento dócil" ou a correção invejosa de Mrs.

${ }^{18}$ Idem, p. 339.

${ }^{19}$ AUSTEN, Mansfield Park, p. 5 (meus destaques). 
Norris como "um espírito de atividade". O recurso à ironia, assim como o manejo magistral do ponto de vista, muito menos unívoco do que pode parecer numa primeira leitura, não só retiraria dos narradores austeneanos, e no limite da autora, a pecha de "moralista inflexível" ${ }^{20}$ que lhe foi atribuída por uma parte da crítica, mas emprestaria à narrativa um alto grau de complexidade e uma boa dose de ambiguidade e indeterminação, atribuindo ao leitor um papel ativo no trabalho de interpretação.

Ler Jane Austen a partir dessas premissas, com atenção às sutilezas da enunciação, às ambiguidades, às armadilhas do discurso, nos remete ao mesmo estilo galhofeiro, corrosivo e oblíquo tão nosso velho conhecido em Machado de Assis, cujos narradores, também eles circulando numa esfera social bastante delimitada - a dos bem-nascidos, bem-postos e aquinhoados com as benesses e privilégios de sua condição -, demonstrarão igual liberdade de perspectiva, por meio da volubilidade "que personifica os múltiplos papéis disponíveis no teatro do mundo histórico-social". ${ }^{21}$ Esse neto de escravos alforriados, portanto também a partir de uma posição periférica, soube examinar como ninguém o "tamanho da sociedade fluminense", ${ }^{22}$ talvez por conhecer bem o tratamento que a classe dominante dispensava aos debaixo. Na sua obra madura, conforme demonstrou Roberto Schwarz, lançará mão do ponto de vista dos senhores para tratar da matéria local e subverter, nesse passo, as convenções do grande romance europeu. Contudo, mesmo nos primeiros romances, Machado arma um ponto de vista que desconstrói, em chave irônica, os temas preferenciais do romance romântico, subvertendo a idealização e os estereótipos que se costumam associar a ele. Ao final de Ressurreição, para lembrar um exemplo, o leitor descobre não apenas a ironia do título, mas também que nessa "ópera bufa com intervalos de música séria"23 o médico Félix, cujo coração renasce pelo amor de Lívia apenas para morrer de novo, "é essencialmente infeliz". ${ }^{24}$

\footnotetext{
${ }^{20}$ BATTAGLIA apud MORINI, The poetics of disengagement: Jane Austen and echoic irony, p. 341.

${ }^{21}$ SOUZA, O romance tragicômico de Machado de Assis, p. 23. Roberto Schwarz determina a volubilidade como o estilo por excelência do narrador machadiano, que ele explica como aquele que "de frase a frase muda de personalidade, de dicção, de gênero literário ou de ponto de vista". Ver SCHWARZ, Uma prosa e suas implicações, p. 105-111.
}

22 ALENCAR, Obra completa, p. 1219. A expressão é de José de Alencar, em comentário sobre suas personagens, mas sugere a necessidade de adaptar o romance europeu ao tamanho do país na ordem do mundo. Ver Carta. O leitor reconhecerá nas observações acima o recurso às leituras de Roberto Schwarz.

${ }^{23}$ ASSIS, Obra Completa, vol. I, p. 182.

${ }^{24}$ Idem, p. 195. 
Mestre no manejo dos temas da tradição europeia, entre os quais seus narradores circulam com familiaridade e desenvoltura, mais à frente ele se valerá da ironia corrosiva e da sátira aos modos de ser da sociedade brasileira para pôr a nu as relações entre os proprietários e os desvalidos, aqueles que sequer eram reconhecidos como sujeitos no âmbito da lei e do direito.

De "seu posto de escuta do mundo", 25 onde se instalou para escrever a crônica da sociedade de seu tempo, Machado empunha o açoite da ironia para lhe narrar as mazelas e expor o grotesco de certos traços da elite brasileira. O tom desabusado - marca registrada dos romances ditos da segunda fase - não poupa indivíduos, acontecimentos, convenções, instituições e atravessa o conjunto de sua obra. O deboche, a crueldade, a agressão verbal frequentam os romances, os contos e as crônicas, e mal se ocultam nas entrelinhas do discurso educado e pretensamente cordial da instância narrativa, o qual é uma armadilha para os leitores desavisados. São esses os que são sistematicamente achincalhados com os comentários os mais ácidos e desrespeitosos. Também não lhe escapam certas personagens, alvo de observações ferinas, como o Viana de Ressurreição, de quem o narrador diz que "[n] asceu parasita como outros nascem anões. Era parasita por direito divino", ${ }^{26}$ ou Eugênia, "a flor da moita", 27 "Vênus Manca", ${ }^{28}$ sobre quem Brás Cubas declara, sem qualquer laivo de piedade:

O pior é que era coxa. Uns olhos tão lúcidos, uma boca tão fresca, uma compostura tão senhoril; e coxa! Esse contraste faria suspeitar que a natureza é às vezes um imenso escárnio. Por que bonita, se coxa? Por que coxa, se bonita? ${ }^{29}$

Resta evidente o quanto de sentimento de superioridade está implícito nesse tratamento dispensado aos outros de gênero, classe e cor. Ou o quanto se exige de seu leitor, em termos de decodificação, numa crônica aparentemente simples e direta, como é o caso daquela publicada em $A$ Semana em 16 de outubro de 1892, sobre a substituição dos bondes de tração animal pelos de tração elétrica. ${ }^{30} \mathrm{~A}$ lembrança das então recentes abolição da

\footnotetext{
25 BRAYNER, As metamorfoses machadianas, p. 65.

${ }^{26}$ ASSIS, cit., p. 120.

${ }^{27}$ ASSIS, Memórias póstumas de Brás Cubas, p. 51.

${ }^{28}$ Idem, p. 54.

${ }^{29}$ Ibidem.

${ }^{30}$ ASSIS, Obra completa, vol. III, p. 550-553.
} 
escravatura e proclamação da República elimina qualquer possibilidade de leitura do diálogo entre os burros na chave da fábula e, naquele contexto, desnuda o que se esconde por trás da novidade e aparente progresso, revestindo a crônica, na verdade, de um sentido alegórico que nos remete aos efeitos deletérios do processo de modernização do país, sempre realizado de forma incompleta. Enquanto a crônica desmente a intenção do narrador de não criticar o "grande ar de superioridade" do cocheiro - "Não é meu ofício censurar essas meias glórias, ou glórias de empréstimo, como lhe queiram chamar espíritos vadios" -, a questão que a encerra, posta pelo burro da esquerda ao receber a lambada no lombo - "- Onde está a justiça deste mundo?" - ${ }^{31}$ ecoa como um comentário irônico não só à situação ali narrada, mas principalmente à outra situação, essa histórica e política, que autoriza o leitor a equiparar os burros da crônica com os escravos recém-libertos, reeditando, dessa maneira, a famosa frase de Antonil, de inícios do século XVIII, para quem, no Brasil, se costumava dizer que para o escravo são necessários três $P$, pão, pau e pano.

Com seu costumeiro desassombro, Machado disseca a vida brasileira nos seus mais variados aspectos. Seus narradores assumem-se como observadores dos homens e do comportamento humano, analisam e anatomizam seus impulsos, paixões e conflitos íntimos, mantendo para isso o necessário distanciamento crítico em relação aos seres e objetos. Também nos romances em primeira pessoa a autoconsciência crítica do narrador se volta contra si mesmo e alarga o intervalo criado pelo desdobramento entre o eu que narra e o eu narrado. Nesse hiato, amplia-se o potencial de ambiguidade que o duplo ponto de vista instala. Assim, descobrimos, por exemplo, que a dissimulação que Bento Santiago atribui a Capitu é, na verdade, procedimento useiro e vezeiro do próprio narrador. Se na Capitu menina já estava contida a mulher - "se te lembras bem da Capitu menina, hás de reconhecer que uma estava dentro da outra, como a fruta dentro da casca" - 32 também o Casmurro do presente tem dentro de si o Bentinho do passado. Assim, os medos e inseguranças do garoto tímido e mimado pela mãe sobrevivem no adulto autocentrado, que

[...] acredita estar envolvido em uma trama trágica, enquanto o narrador sabe, e assinala para o leitor, que este engano não passa de uma

\footnotetext{
${ }^{31}$ Idem, p. 551 e 553, respectivamente.

32 ASSIS, cit., p. 944.
} 
indulgente hipocrisia com a qual o frouxo personagem procura dar certo lustro à sua triste inépcia prosaica. ${ }^{33}$

A ironia do narrador revelaria, nesses termos, "o abismo que separa a estrutura do drama trágico de Otelo do dramalhão de Bentinho"34 e acrescentaria elementos ao perfil psicológico da personagem para que o leitor possa melhor avaliar suas reações e afetos, não apenas em relação à própria Capitu, mas também aos outros componentes desse triângulo, ou poderíamos sugerir quadrilátero, incluindo Sancha na equação?

Sobrelevam, nessas ocasiões, as inconsistências, as incongruências, os contrastes e as associações inusitadas por parte do narrador, os quais provocam a quebra de expectativa, invertem o sentido e introduzem um significativo grau de incerteza e indeterminação que minam qualquer interpretação unívoca pelo leitor. Não tem qualquer validade, portanto, aquela advertência do pai ao filho, em "Teoria do Medalhão":

- Somente não deves empregar a ironia, esse movimento ao canto da boca, cheio de mistérios, inventado por algum grego da decadência, contraído por Luciano, transmitido a Swift e Voltaire, feição própria dos céticos e desabusados. ${ }^{35}$

O "movimento ao canto da boca", a atitude cética e desabusada são justamente as armas do humor cáustico e da agudeza com que acompanhamos os meneios do narrador na construção de seu discurso. A notória desfaçatez com que desmontam os truísmos, suspendem as verdades estabelecidas e instauram a ambiguidade filia os narradores machadianos à linhagem justamente dos escritores que o pai aconselha o filho a evitar, como Luciano, Swift e Voltaire, e os inscreve na tradição de ainda outros predecessores célebres como Fielding e Sterne, que Machado reconheceu e incorporou, e de quem toma de empréstimo a técnica da intrusão e das digressões. Na esteira de Cervantes, mestre e modelo comum dos britânicos e do brasileiro, eles erigem a autoconsciência narrativa em procedimento e método. Por esse viés, a narrativa se revela, em uma de suas dimensões, uma reflexão sobre o próprio ato da escrita, pontilhando o relato com um sem-

\footnotetext{
33 ROSENFIELD, A ironia de Machado em Dom Casmurro: reflexão sobre a cordialidade anti-trágica, p. 81.

${ }^{34}$ Ibidem.

${ }^{35}$ ASSIS, Obra completa, vol. II, p. 294.
} 
número de observações atinentes ao universo do livro e da leitura, assim como da estrutura formal do próprio romance:

Aqui é que eu quisera ter dado a este livro o método de tantos outros, velhos todos, - em que a matéria do capítulo era posta no sumário: "De como aconteceu isto assim, e mais assim". Aí está Bernardim Ribeiro; aí estão outros livros gloriosos. Das línguas estranhas, sem querer subir a Cervantes nem a Rabelais, bastavam-me Fielding e Smollett, muitos capítulos dos quais só pelo sumário estão lidos. Pegai em Tom Jones, livro IV, cap. I, lede este título: Contendo cinco folhas de papel. É claro, é simples, não engana a ninguém; são cinco folhas, mais nada, quem não quer não lê, e quem quer lê, para os últimos é que o autor concluiu obsequiosamente: "E agora, sem mais prefácio, vamos ao seguinte capítulo". ${ }^{36}$

A filiação é explícita, portanto. Descontada a autoirrisão contida na ideia de que seus modelos são livros "velhos todos" ou de que o livro que escreve como defunto autor alcançará "nem cinquenta, nem vinte, e quando muito, dez. Dez? Talvez cinco" leitores, ${ }^{37}$ há todo um universo literário de referência que sublinha o caráter metaficcional do que ele escreve e do que se lê. Na obra de Machado, além dos usos habituais (seja verbal, seja situacional), ${ }^{38}$ a ironia deixa de ser apenas figura de linguagem e ganha ainda outra dimensão, pois incorpora mais um sentido, aquele de parábase - a função crítica que o narrador autorreflexivo assume ao suspender a narrativa para introduzir seus comentários e análise. ${ }^{39}$ São exemplos os prólogos, as

\footnotetext{
${ }^{36}$ ASSIS, Quincas Borba, p. 220.

${ }^{37}$ ASSIS, cit., p. 12.

38 Veja-se como exemplo de ironia de situação o caso de Jacó, referido no capítulo LXXXVII ("Geologia"), de Memórias póstumas de Brás Cubas. Descrito como "a probidade em pessoa", Jacó, ao ser procurado pelo enfadonho Dr. B., primeiro manda dizer que não estava em casa e, depois, vê-se obrigado a receber a visita. Diante disso, Brás Cubas, que presenciou a cena, faz a seguinte constatação: "Retirou-se o Doutor B. e respiramos. Uma vez respirados, disse eu ao Jacó que ele acabava de mentir quatro vezes, em menos de duas horas: a primeira, negando-se; a segunda, alegrando-se com a presença do importuno; a terceira, dizendo que ia sair; a quarta, acrescentando que com a mulher. Jacó refletiu um instante, depois confessou a justeza da minha observação, mas desculpou-se dizendo que a veracidade absoluta era incompatível com um estado social adiantado, e que a paz das cidades só se podia obter à custa de embaçadelas recíprocas...". ASSIS, cit., p. 98.

${ }^{39}$ Parábase: "no antigo teatro antigo, espécie de intermédio crítico ou cômico feito pelo coro enquanto o palco estava vazio, em que muitas vezes expunha o autor as suas opiniões ao público" (Dicionário Caldas Aulete); "na comédia grega, ocasião em que o coro se afastava da ação teatral e trazia o público
} 
frequentes interrupções do curso da narrativa para se dirigir ao leitor, a discussão dos impasses da construção ficcional, os comentários sobre a materialidade do livro ou sobre a própria tradição literária, todos eles procedimentos que desnudam as engrenagens e o travejamento da narrativa, criando o efeito irônico e adensando o estatuto de artefato conferido à escrita.

No seu significado de eirōneía $-{ }^{40}$ questionamento -, a ironia ultrapassa o plano da simples Retórica e vem a se constituir como um instrumento de conhecimento e interpretação do mundo, exibindo as contradições e natureza incongruente dele. ${ }^{41} \mathrm{O}$ romance escancara seus artifícios e transforma a instância narrativa em um espaço de exercício sistemático da anatomia, no sentido que lhe deu Robert Burton em The Anatomy of Melancholy (1621), definida por Northrop Frye como "uma dissecação ou análise [que] expressa com muita precisão a abordagem intelectualizada de sua forma", e que teve em Tristram Shandy de Laurence Sterne um representante paradigmático e modelar no romance moderno. ${ }^{42}$ Dentro dessa ótica, a ironia é uma atitude de pensamento que submete tudo e todos a exame e cujo caráter é essencialmente dialético, uma vez que instaura o princípio da contradição - desde aquela entre o ser e o parecer, aquela entre a realidade e a ficção, até aquela entre o homem e o mundo. Nesse espaço intervalar, instalam-se as disparidades e os despropósitos, instituem-se a relatividade e o dialogismo que parte da fortuna crítica machadiana apreende na obra do escritor brasileiro. Como sugere Sonia Brayner, pelo recurso à paródia, que estiliza os mais diversos discursos (da lei, da ciência, da filosofia, da literatura), a atitude do narrador machadiano, ao assumir as mais variadas máscaras, torna-se substancialmente dialógica pelo entrecruzamento de vozes que ela favorece. ${ }^{43}$ Estaria aí, nessas alusões e

de volta à realidade, abordando temas políticos e sociais" (Dicionário Houaiss). Friedrich Schlegel sustenta que "a ironia é uma parábase permanente" (Fragmento 668, Philosophische Lehrjahre, 17961806). SOUZA, cit., p. 36.

40 Eironeía (ou eirōneía, na transliteração mais exata), com os seguintes sentidos: dissimulation; ignorance purposely affected to provoke or confound an antagonist, a mode of argument used by Socrates; generally, mock-modesty, sarcasm, understatement; pretence, assumption. O substantivo vem do verbo eírō (eilrw), falar, dizer. Ver: LIDDELL; SCOTT; JONES, Greek-English Lexicon with a Revised Supplement. Agradeço a Giuliana Ragusa o esclarecimento.

${ }^{41}$ Para uma discussão mais detalhada do papel da parábase em Machado, ver Ronaldes de Melo e Souza. SOUZA, cit.

42 FRYE, Anatomia da crítica: quatro ensaios, p. 476.

${ }^{43}$ BRAYNER, cit. 
profusão de ecos de pensamentos e elocuções, o material por excelência da perspectiva irônica, que põe em suspensão a expressão unívoca de uma única verdade e de um único ponto de vista.

A estilização dos discursos de outrem, as citações e as referências que encontramos tanto no texto austeniano quando no texto machadiano são procedimentos comuns do ironista e, se a postura do narrador de Austen aparenta maior sobriedade e moderação, é apenas isso - aparência. Como vimos, por trás da polidez, da fala educada e bem-comportada, esconde-se a ferroada que Peter Gay associou ao humor que é, para ele, "em larga medida - um ato de agressão", com um grande potencial de destruição que investe contra "os valores aceitos, os ideais aceitos, as certezas aceitas com todos os recursos do desrespeito". ${ }^{44}$

À linhagem dos humoristas, ironistas e satiristas ingleses, com os quais Machado sugeriu ter afinidades intelectuais, podemos, sem medo, acrescentar o nome de Jane Austen, pois o colóquio apenas aparentemente inverossímil entre eles, longe de ser aleatório ou arbitrário, se funda na percepção de que ambos pertenceram ao mesmo ramo da tradição cômica, compartilharam uma visão desencantada do mundo e dos homens, com sua hipocrisia, cinismo e seus pequenos atos de mesquinharia que os narradores do escritor brasileiro e as personagens da romancista inglesa exibem a mancheias. Quanto aos nossos dois autores, eles não têm nada de inofensivo, mas é nas entrelinhas que podemos perceber o desprezo que nutriam pela sociedade de seu tempo. Se por vezes o insulto se mascara na linguagem educada dos seus narradores e personagens, se em outras ocasiões Machado e Austen parecem se dirigir a um público seleto - aos leitores sagazes, cultos e sensatos que apreendem suas sutilezas e elipses -, ainda assim, em ambos os casos, o "ódio controlado" que poderia ser igualmente atribuído aos dois foi, como sugeriu Harding a respeito de Jane Austen, ${ }^{45}$ uma estratégia de sobrevivência em um mundo que parecia desagradar a ambos em igual medida. Em uma carta a George Pellew, datada de 1883, Henry James se refere à "estreiteza do horizonte social" de Miss Austen, no qual circulam protagonistas em "their small gentility and front parlour existence". ${ }^{46}$ Isso não impediu a romancista inglesa, por meio de sua voz irônica, de apontar o que se ocultava por baixo da civilizada ordem social inglesa e distribuir

\footnotetext{
${ }^{44}$ GAY, The Bite of Wit, p. 327.

${ }^{45}$ HARDING, cit.

${ }^{46}$ JAMES, Selected Letters, vol. II, p. 189.
} 
estocadas, como aquela de Henry Tilney, em Northanger Abbey, que emenda ao seu elogio ao bom senso e aos valores ingleses a ferina observação de que estão todos cercados por "a neighbourhood of voluntary spies" ${ }^{47}$ Não era menos acanhado e provinciano o Rio de Janeiro da época de Machado, que também fustigou com a insolência e as agressões de seus narradores a casta de bajuladores, de vizinhos interesseiros, de jovens casadoiras, de viúvas ricas ou fofoqueiras, de um lado, mas também dos pobres e dependentes, de outro, desnudando o modo de funcionamento das relações sociais sob a capa da prosa elegante e culta de homem civilizado.

\section{Referências}

ALENCAR, José de. Obra completa. Rio de Janeiro: José Aguilar, vol. I, 1959.

ASSIS, Machado de. Obra completa. Rio de Janeiro: Nova Aguilar, vol. I, 1992. . Obra completa. Rio de Janeiro: Nova Aguilar, vol. II, 1993. . Obra completa. Rio de Janeiro: Nova Aguilar, vol. III, 1992. . Memórias póstumas de Brás Cubas. São Paulo: Ática, 1977. . Quincas Borba. São Paulo: Penguin Classics, Companhia das Letras, 2012.

AUSTEN, Jane. Mansfield Park. New York: W.W. Norton \& Company, 1998. Orgulho e preconceito. Trad. Alexandre Barbosa de Souza. São Paulo:

Penguin Classics Companhia das Letras, 2011. . Persuasion. London: John Murray, 1818, 4 volumes. Persuasion. London: Penguin Books, 1985. Pride and Prejudice. London: Penguin Books, 1985. Northanger Abbey: Harmondsworth, 1975.

AUSTEN-LEIGH, James Edward. A Memoir of Jane Austen. London: Richard Bentley, 1870.

BRAYNER, Sonia. As metamorfoses machadianas. In: Labirinto do espaço romanesco. Tradição e renovação da literatura brasileira: 1880-1920. Rio de Janeiro: Civilização Brasileira; Brasília: INL, 1979, p. 51-118.

COHN, Dorrit. Transparent Minds: Narrative Modes for Presenting Consciousness in Fiction. Princeton: Princeton University Press, 1978, p. 108.

FRYE, Northrop. Anatomia da crítica: quatro ensaios. Trad. Marcus de Martini. São Paulo: É Realizações, 2014.

GAY, Peter. Peter Gay. The Bite of Wit.In: Proceedings of the American Philosophical Society, vol. 135, n. 3, 1991.

${ }^{47}$ AUSTEN, Northanger Abbey, p. 199. 
GLEDSON, John. 1872: "A parasita azul". Ficção, nacionalismo e paródia. Cadernos de Literatura Brasileira: Machado de Assis. São Paulo: Instituto Moreira Salles, n. 23 e 24, julho de 2008, p. 163-218.

GUIMARÃES, Hélio de Seixas. Machado de Assis e o paradigma inglês. In: SECCHIN, Antonio Carlos; BASTOS, Dau; JOBIM, José Luís (org.). Machado de Assis. Novas perspectivas sobre a obra e o autor, no centenário de sua morte. Rio de Janeiro: De Letras; Niterói: EdUFF, 2008, p. 39.

HARDING, D.W. Regulated Hatred: an aspect of the work of Jane Austen. In: WATT, Ian (ed.). Jane Austen: a collection of critical essays. Englewood Cliffs, N.J.: Prentice Hall, 1963, p. 166-179.

JAMES, Henry. Selected Letters, ed. Leon Edel. Library of Congress, 1987.

LE FAYE, Deirdre. Jane Austen's Letters. Oxford : Oxford University Press, 1997.

LIDELL, H. G.; SCOTT, R.; JONES, R. Greek-English Lexicon with a Revised Supplement. $9^{\text {th }}$ ed. Oxford: Clarendon Press, 1996.

MORINI, Massimiliano. Jane Austen's Narrative Techniques: A Stylistic and Pragmatic Analysis. Farnham and Burlington, VT: Ashgate, 2009, p. 27-53.

The poetics of disengagement: Jane Austen and echoic irony. Language and Literature, 19, n. 4, p. 339-356, 2010.

ROSENFIELD, Kathrin. A ironia de Machado em Dom Casmurro: reflexão sobre a cordialidade anti-trágica. Revista Letras (Santa Maria), v. 32, p. 71-90, 2007.

SCHWARZ, Roberto. "Uma prosa e suas implicações". Língua e Literatura, 1985, 14, p. 105-111.

SOUZA, Ronaldes de Melo e. O romance tragicômico de Machado de Assis. Rio de Janeiro: EdUERJ, 2006.

WATT, Ian. Jane Austen and the Traditions of Comic Aggression. In: The Literal Imagination: selected essays. Palo Alto: The Society for the Promotion of Science and Scholarship; Stanford: The Stanford Humanities Center, 2002, p. 159-170.

WILLIAMS, Raymond. O campo e a cidade: na história e na literatura. Trad. Paulo Henriques Britto. São Paulo: Companhia das Letras, 1989, p. 228-229. [The Country and the City. London: The Hogarth Press, 1993].

SANDRA GUARDINI TEIXEIRA VASCONCELOS é professora titular de Literatura Inglesa e Comparada na Universidade de São Paulo. Fez pós-doutorado na Universidade de Cambridge e na Universidade de Manchester e foi Visiting Research Associate no Centre for Brazilian Studies da Universidade de Oxford. Nos últimos anos, desenvolve pesquisa sobre as relações entre 0 romance inglês dos séculos XVIII e XIX e o romance brasileiro do século XIX, para a qual conta com uma Bolsa de Produtividade em Pesquisa do CNPq (1A). Além de traduções e da organização de vários livros, tem artigos e capítulos de livros publicados no Brasil e no exterior e é autora de Puras misturas. Estórias em 
Guimarães Rosa (Hucitec/FAPESP, 1997), Dez lições sobre o romance inglês do século XVIII (Boitempo, 2002) e A formação do romance inglês: Ensaios Teóricos (Hucitec/Fapesp, 2007) - Prêmio Jabuti de Teoria/Crítica Literária de 2008. É curadora do Arquivo João Guimarães Rosa do Instituto de Estudos Brasileiros e Diretora da Biblioteca Brasiliana Guita e José Mindlin (USP). E-mail: <sgtvasco@usp.br>

Recebido: 12.09 .14

Aprovado: 30.10 .14 